\title{
Investigation and Discussion of Equivalent Transferring Method of Vertical Drains
}

\author{
Binbin $\mathrm{Xu}^{1, \mathrm{a}}$ and Dongjun $\mathrm{Li}^{2, \mathrm{~b}}$ \\ ${ }^{1}$ Tianjin Port Engineering Institute Ltd. of CCCC, Tianjin, China; Key Lab. of Geotechnical \\ Engineering of Tianjin, Tianjin, China; Key Lab. of Geotechnical Engineering, Ministry of \\ Communication, Tianjin, China; \\ 2 Tianjin Port Engineering Institute Ltd. of CCCC, Tianjin, China. \\ axubinbin@tpei.com.cn, b272746353@qq.com
}

Keywords: numerical calculation, equivalent transferring, sand wall, equivalent permeability, drainage function.

\begin{abstract}
The drainage consolidation method is widely used in the soft ground to increase its strength and decrease its deformation. One of the difficulties in the calculation of drainage consolidation is the simulation of the vertical drains. The common method is the equivalent transferring method from the axial-symmetric sand well to the plane-strain sand wall based on the equal degree of consolidation at various stages. Because the corresponding point-to point relationship would be lost during this transformation, it is impossible to predict the horizontal displacement and pore pressure accurately. From the macro-view, the installation of vertical drains acts as the improvement of the permeability of the ground or the acceleration of the seepage of the pore water. Therefore, the equivalent permeability method or the method treating the well as drainage function is preferred to be recommended.
\end{abstract}

\section{Introduction}

As the development of national economy, there is a big progress in the infrastructure construction, in which the construction on the soft ground attracted most of the attention. The constructions to be constructed mainly concentrate around the coastal area of east of China, in which the coastline consists of silty soft soil due to river/sea erosion and sedimentation. Such kinds of soil are of high water content, high void ratio, high compressibility, low strength and low permeability. Once the construction is directly constructed on the soft ground, there would be significant deformation of uneven settlement due to the consolidation of ground and the duration of consolidation is usually very long, which may influence the servility of the building. In addition, low bearing capacity of the ground may result in the instability of the building. Therefore, it is very necessary to carry out ground improvement before the construction.

For the soft ground, the most frequently used method is drainage consolidation method such as vacuum preloading method, surcharge preloading method or vacuum combined surcharge preloading method considering its feasibility and economy.

\section{Investigation of Equivalent Method}

Research Review. As it is well known, soil-water coupled elasto-plastic finite element method is one of the most powerful tools to forecast the ground deformation. For the horizontal drainage consolidation calculation contains the sand well or plastic vertical drains, one of the problems is how to realize the drainage passage or transferring of vacuum. After near 60 years study, there have been mainly three dealing methods: 1 ) the finite elements directly designated to the drainage passage; 2 ) the equivalent method converting the drainage passage from three dimensional sand drains to two dimensional sand walls; 3 ) the equivalent permeability method.

Indraratna et al.[1-3] research the method transferring from the single drain to unit length of sand wall. The method is that the average degree of consolidation of both sand drain and sand wall at 
arbitrary depth and time is equal through adjusting the permeability coefficient and space of the sand wall. The well resistance and smearing effect are also taken into consideration. But the equal-strain condition is only satisfied vertically, the horizontal deformation of the ground cannot be reflected using this method. Sanchez et al. [4], Hird et al. [5-6] gave the similar transferring method according to the equal horizontal degree of consolidation. However, Hird didn't consider the smearing effect, horizontal displacement and vertical seepage. Zhao et al. [7] gave the analytical solution of equal strain considering the horizontal displacement and vertical seepage, which is also compared with Barron's solution. When using this method, it is necessary to modify the permeability, while the space of the sand wall can be determined arbitrarily according to the mesh division. Chai et al. [8-10] proposed a method transfer the ground with sand drain to homogeneous ground and then Bergado et al. [11] calculated the ground of Bangkok international airport improved by vacuum and surcharge preloading method using this method. Kim et al. [12] considered the transferring using equal degree of consolidation at $60 \%$ and $90 \%$. Amir et al. [13] researched the method transferring the ground with sand drain to one-dimensional homogeneous ground and believed that the function of sand drain is to improve the permeability of the ground. In the above transferring method, the settlement of the ground is basically satisfactory, but because there is no one-to-one relationship for the points before and after the transformation, the pore water pressure cannot be forecasted.

Although some of the calculations have solved the prediction of ground settlement, the calculation of horizontal displacement and excess pore water pressure is not so accurate. The theoretical method can only be used when the boundary condition and loading pattern is simple. When using the finite element method, one of the problems for the conversion from three-dimensional sand drains to two dimensional sand walls. Because the deformation and seepage of the ground with sand drain are three dimensional, the suitable analyzing method is three dimensional. However, it is too heavy to carry out the calculation and usually the calculation is based on the plane strain condition. How to transfer the three-dimensional sand drain to two-dimension is always the highlight.

Transferring Methods. As has been mentioned above, the general treatment for the axial-symmetric sand well is transferring to plane-strain sand wall, as shown in Fig. 1. The size, permeability, well resistance etc. under two conditions can be transferred accordingly and next some common transferring methods are introduced.

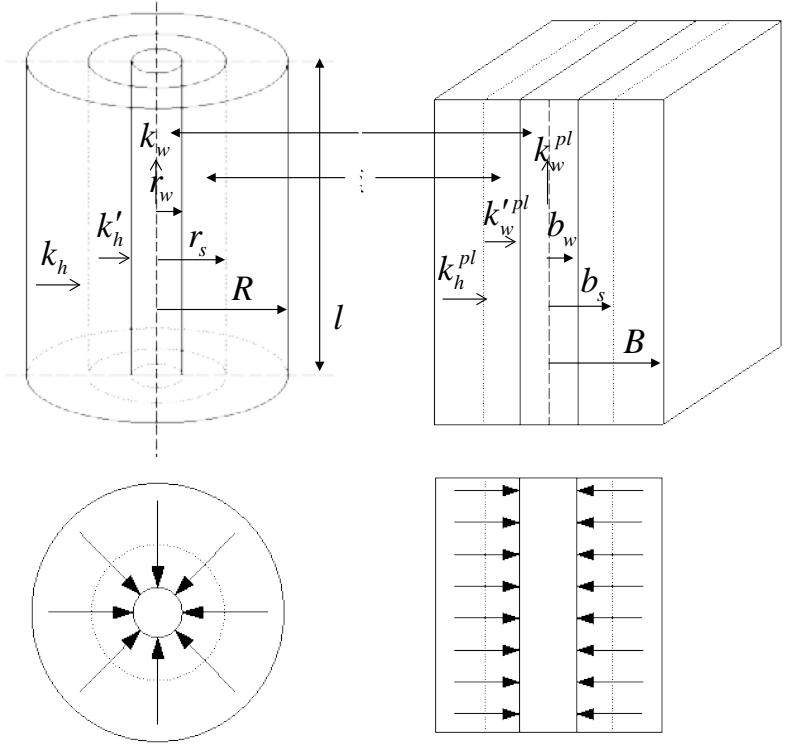

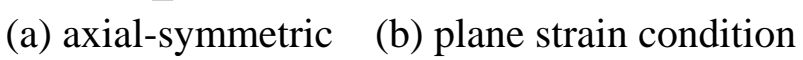

Fig. 1 Equivalent transferring between sand well and sand wall

(1) $50 \%$ consolidation degree is equal

Shinsha et al. [14] firstly proposed a transferring principle with clear concept, namely during the transferring the 50\% degree of consolidation between two conditions should be equal. Then the relationship between the permeability $k_{a x}$ of axial symmetry and the permeability $k_{p l}$ of plane strain is as follows: 


$$
\frac{k_{p l}}{k_{a x}}=\left(\frac{B}{D_{e}}\right)^{2}\left(\frac{T_{h 50}}{T_{r 50}}\right) .
$$

Here, $B$ and $T_{h 50}$ are the space length and the time factor when the consolidation degree is $50 \%$ under plane strain condition respectively. $D_{e}$ and $T_{r 50}$ are the space length and the time factor under axial symmetric condition.

(2) Average consolidation degree is equal

Hird et al. [6] believed that the average consolidation degree under two conditions at arbitrary time and arbitrary depth is equal without considering the well resistance and the transferring equation is as shown in Eq. 2.

$$
\frac{k_{p l}}{k_{a x}}=\frac{2 B^{2}}{3 R^{2}\left[\ln \left(\frac{R}{r_{s}}\right)+\left(\frac{k_{a x}}{k_{s}}\right) \ln \left(\frac{r_{s}}{r_{w}}\right)-\frac{3}{4}\right]} .
$$

Here, $R, r_{w}$ and $r_{s}$ represent the radius of soil element, sand well and smearing zone and the following parameters is the same as above. As can be seen in Eq. 2, if $k_{p l}=k_{a x}$, the relationship between $B$ and $R$ can be obtained. If $B=R$, the relationship between $k_{a x}$ and $k_{p l}$ can be obtained similarly.

(3) Average consolidation degree is equal considering well resistance

Based on Hird's method, Chai et al. [8] gave a transferring method taking the well resistance into consideration and the relationship is shown in Eq. 3.

$$
q_{w}^{p l}=\frac{4 k_{h} l^{2}}{3 B\left[\ln \left(\frac{n}{s}\right)+\left(\frac{k_{h}}{k_{h}^{\prime}}\right) \ln (s)-\frac{17}{12}+\frac{2 l^{2} \pi k_{h}}{3 q_{w}^{a x}}\right] .}
$$

Here, $q_{w}^{p l}$ and $q_{w}^{a x}$ are the drainage capacity of the vertical drainage under plane-strain and axial-symmetric conditions respectively.

(4) Equivalent permeability method

Chai et al. [10] proposed a simple method to calculate the drainage problem where the installation of vertical drains can be regarded as the improvement of the vertical permeability of the ground and the transferring equation is shown in Eq. 4.

$k_{v e}=\left(1+\frac{2.5 l^{2}}{\mu D_{e}^{2}} \frac{k_{h}}{k_{v}}\right)$.

\section{Discussions of Equivalent Methods}

For the usual equivalent methods, the vertical consolidation degree at different stages is emphasized in the transferring process, which is to satisfy the vertical deformation of the ground. It can be understood as a compromise between the vertical and horizontal deformation. In order to solve the problem of low efficiency in computation, Sekiguchi et al. [15] proposed a simple calculation method which is called macro-element method. In this method, the vertical drainage is simplified as the drainage function and its mechanical properties can be ignored. Therefore, it is unnecessary to designate detailed elements to the drainage materials so that the calculation efficiency would be improved greatly. Actually, this method is similar to the equivalent permeability method. Starting from the seepage theory, the drainage path between the drainage passage and the ground is not considered and the consolidation is accelerated via the drainage function inside the improved element. The merit of this method lies in the combination with usual finite element software closely by only adding the drainage function during the finite discretization. 


\section{Conclusions}

One of the problems for the horizontal drainage calculation is the treatment of the drainage well in the ground. In this paper, the transferring methods are investigated and discussed by literature review and the conclusions are as follows:

1) The equivalent transferring methods from the axial-symmetrical sand well to the plane-strain sand wall are usually based on the same degree of vertical consolidation at various stages. The advantage lies in that the vertical deformation of the ground can be simulated perfectly while the disadvantages are the poor prediction of the horizontal displacement and pore water pressure, because there is no point-to point relationship before and after the model.

2) From the macro-view, the installation of the vertical drains actually acts as the improvement of the permeability of ground or the enhancing of the drainage rate. Therefore, the equivalent permeability method or the macro-element method can be the preferred chose in the calculation.

\section{References}

[1] B. Indraratna and I. W. Redana, Plane strain modeling of smear effects associated with vertical drains. J. Geotech. and Geoenviron. Engrg. ASCE. 1997(5): 474-478.

[2] B. Indraratna and I. W. Redana, Closure: Plane strain modeling of smear effects associated with vertical drains. J. Geotech. and Geoenviron. Engrg. ASCE. 1999(1):96-99.

[3] B. Indraratna and L W. Redana, Numerical modeling of vertical drains with smear and well resistance installed in soft clay. Can. Geotech. J., 2000(1):132-145.

[4] J.M. Sanchez and C. Sagaseta, Analysis of staged construction of embankments on soft soil, Proc. $2^{\text {nd }}$ European speciality conference on numerical methods in geotech. engrg., 1990:457-471.

[5] C. C. Hird, I. C. Pyrah and D. Russel, Finite element modeling of vertical drains beneath embankments on soft ground. Geotechnique, 1992(4):499-511.

[6] C. C. Hird, D. Russel and F. Cinicioglu, Modeling the effect of vertical drains in two dimensional finite element analysis of embankments on soft ground. Can. Geotech. J. 1995: 795-807.

[7] WB Zhao, YH Chen, YP Gong, A methodology for modeling sand-drain ground in plain strain analysis, Journal of Hydraulic Engineering, 1998(6):53-57.

[8] J. C. Chai, N. Miura and D. T. Bergado, Behavior of vertical drain improved subsoil under embankment loading. Soils and Foundations. 1995 (4): 49-61.

[9] J. C. Chai, and N. Miura, Investigation of factors affecting vertical drain behavior. J. Geotech. and Geoenviron. Engrg., ASCE. 1999(3):216-226.

[10] J. C.Chai, S. L.Shen N.Miura and D. T.Bergado, Simple method of modeling PVD-Improved subsoil. J. Geotech. and Geoenviron. Engrg. ASCE. 2001(11):965-972.

[11] D. T.Bergado J. C.Chai, N.Miura and A.S.Balasubramaniam, PVD improvement of soft Bangkok clay combined vacuum and reduced sand embankment preloading. Geotech. Engrg.J. 1998(1): 95-122

[12] Y. T.Kim and S.R.Lee An equivalent model and back-analysis technique for modeling in situ consolidation behavior of drainage-installed soft deposits, Computer and Geotechnics, 1997(2): 125-142.

[13] M.A.Amir and L.R.Herrmann Continuum model and analysis of wick-drained systems, International Journal for Numerical and Analytical Methods in Geomechanics, 1993(17): 827-847. [14] Shinsha et al., Consolidation settlement and lateral displacement of soft ground improved by sand-drains [J]. Japan Soc. Soil Mech. and Found. Eng., 1982, 30(2): 7-12.

[15] Sekiguchi H., Shibata T., Fujimoto A. and Yamaguchi H., A macro-element approach to analyzing the plane strain behavior of soft foundation with vertical drains. Proceedings of the 31st Symposium of the Japanese Geochemical Society, 1986 111-116 